\title{
AS ORIGENS DAS MARCAS E DA PUBLICIDADE \\ MODERNA: AS CAMPANHAS PUBLICITÁRIAS DE SABÕES E SABONETES
}

The origins of brands and modern advertising: Soap's advertising campaigns

\section{Los orígenes de las marcas y la publicidad moderna: Las campañas publicitarias de jabones}

António Machuco Rosa ${ }^{1}$

\section{Resumo}

Neste artigo é analisado o surgimento das marcas e da publicidade moderna através do exemplo das campanhas publicitárias de sabões e sabonetes no início do século XX. Serão analisadas as campanhas de Woodbury's e de Lux, sublinhando-se o papel que a agência J. Water Thompson teve nessas campanhas. Mostra-se que no início do século XX já existiam duas grandes tendências na criação de campanhas publicitárias, a publicidade "reason-why e a publicidade "emocional". Mostra-se finalmente como essas duas tendências estão associadas a duas conceções sobre o papel das marcas registadas.

Palavras-chave: publicidade, marcas, Woodbury's, Lux, triângulo semiótico.

\begin{abstract}
In this article, it is analyzed the emergence of brands and modern advertising through the example of advertising campaigns of soap in the early twentieth century. The campaigns of Woodbury's and Lux are analyzed, stressing the role that the advertising agency J. Walter Thompson had in these campaigns. It is shown that in the early twentieth century there were already two major trends in advertising campaigns, "reason why" advertising and "emotional" advertising. It is finally shown how these two trends are related to two conceptions of the role of trademarks.
\end{abstract}

Keywords: advertising, brands, Woodbury's, Lux, semiotic triangle.

\section{Resumen}

${ }^{1}$ Professor Associado - Faculdade de Letras da Universidade do Porto - Departamento de Ciências da Comunicação e da Informação. E-mail: machuco.antonio@gmail.com 
As origens das marcas e da publicidade moderna: As campanhas publicitárias de sabões e sabonetes

de António Machuco Rosa

En este artículo, se analiza la aparición de las marcas y la publicidad moderna a través del ejemplo de las campañas de publicidad de jabón a principios del siglo XX. Se analizan las campañas de Woodbury's y Lux, haciendo hincapié en el papel que la agencia de publicidad J. Walter Thompson tenía en estas campañas. Se muestra que a principios del siglo XX ya existían dos tendencias principales en las campañas de publicidad, la publicidad llamada "reason why," y la publicidad "emocional". Se muestra, por último, cómo estas dos tendencias están relacionadas con dos concepciones del papel de las marcas.

Palabras-clave: publicidad, marcas, Woodbury’s, Lux, triángulo semiótico.

\section{INTRODUÇÃO}

A emergência do consumidor moderno ocorreu a partir de meados do século XIX devido ao surgimento dos grandes armazéns, das marcas comerciais visando os mercados nacionais e, de seguida, da publicidade que vai servir de suporte a essas marcas. Os grandes armazéns, como o Bom Marché, em França, Baimbridge em Inglaterra e Macy nos Estados Unidos, quebraram o anterior e tradicional sistema de contacto direto entre o tradicional pequeno lojista vendendo a granel e o seu cliente. Eles passaram a comprar diretamente ao fabricante, posicionando-se como um mediador para o comprador final. As novas superfícies comerciais passaram também a dispor de uma grande variedade de produtos expostos, diante dos quais desfilava um número crescente de potenciais clientes. Apelavam assim a um consumo de massas (cf. WILLIAMS, 1982). Ao mesmo tempo, as novas superfícies incentivaram o empacotamento estandardizado dos bens de consumo. Os produtos apareceram cada vez mais sob o rótulo de marcas e, na medida em que são espaços onde múltiplos produtos com funcionalidades similares são expostos, os grandes armazéns contribuíram também para o processo de diferenciação das marcas.

Foi sensivelmente no mesmo período, sempre na segunda metade do século XIX, sobretudo nos Estados Unidos, que surge o moderno conceito de marca. A marca comercial em sentido moderno contribuiu também para o corte radical com a venda a granel de produtos genéricos. Os grandes armazéns contribuíram para a sua difusão, mas não foram a sua única causa. $\mathrm{Na}$ origem das marcas modernas esteve também a 
As origens das marcas e da publicidade moderna: As campanhas publicitárias de sabões e sabonetes

formação dos mercados nacionais que, com o desenvolvimento dos novos meios de comunicação (a começar pelo caminho de ferro), se tornaram coextensivos com a dimensão do próprio país nos quais eles assentavam. Esses novos mercados vão constituir uma oportunidade para certos fabricantes que vão progressivamente confrontar-se com o tradicional produtor totalmente orientado para o seu mercado local de origem. Os fabricantes orientados para o mercado nacional unificado vão então encarar o problema de ter que diferenciar os seus produtos dos produtos similares que eram produzidos pelos fabricantes locais. A solução do problema consistiu em designar, através de uma marca, os produtos que visavam o mercado nacional, diferenciando-os desse modo dos produtos locais similares. De seguida, isso teve como consequência a própria consolidação de um mercado à escala de um país, num processo de feedback em que os mercados nacionais fizeram emergir as marcas e as marcas consolidaram os mercados nacionais (COCHOY, 1999) Simultaneamente, os fabricantes nacionais desejavam que existissem preços uniformes na totalidade do seu mercado alvo, pelo que as marcas surgiram também como uma forma de controlar, e aumentar, os preços dos produtos: a uma certa marca ficava associado um certo preço, usualmente bem mais elevado do que o do produto genérico correspondente (MAZA, 1999: 163 e seq.).

Uma das consequências mais imediatas da introdução de marcas foi que, progressivamente, o produto genérico vendido a granel pelo produtor ao consumidor deixou de ser a principal forma de comercialização. Começaram a aparecer produtos designados por uma marca tornada visível através de um nome e de um logótipo inscritos num pacote ou garrafa standard que tipificavam a marca em questão. E para ainda mais reforçar a diferença dos produtos nacionais em relação aos produtos genéricos locais, as primeiras marcas insistiram na sua genuinidade: apenas uma certa marca corresponderia realmente ao produto genérico que lhe subjazia. A marca surge assim, inicialmente, como uma certificação de autenticidade que traduz uma estreita ligação ao próprio produto. Como se verá mais adiante neste artigo, inicialmente uma marca foi concebida como uma forma de dizer que o produto que a ostenta tem realmente uma certa origem, o que era conseguido por a marca reenviar muitas vezes para o próprio nome do indivíduo (ou empresa) que tinha criado esse produto. Ver-se-á igualmente que essa conceção inicial do papel da marca está de acordo com as leis sobre o conceito de marca registada: o seu fundamento reside no facto de o registo legal de 
As origens das marcas e da publicidade moderna: As campanhas publicitárias de sabões e sabonetes

de António Machuco Rosa

uma marca ter como finalidade diferenciar um produto de um outro, identificando a empresa no qual ele se origina e protegendo assim os consumidores, isto é, garantindo que eles não são enganados por um produto que reclama ser aquilo que não é (cf., por exemplo, MCCARTHY, 1996). Nesse sentido, será sublinhado que o conceito de marca registada apenas é adequadamente compreendido se se tiver presente que ele é uma instância da relação triangular de signo, tal como foi definida por Charles S. Peirce.

Permanecendo no período histórico inicial das marcas, pode afirmar-se que a publicidade, na transição do século XIX para o século XX, é genericamente caracterizada por ser "informativa", identificando o produto e sua origem, e salientando a utilidade derivada do consumo do produto, com particular insistência nos benefícios para a saúde e bem-estar corporal. Esse tipo de publicidade sobretudo informativa, e referindo a utilidade que pode ser retirada do produto, vai em alguns casos ser substituída por um outro tipo de anúncios que apontam para outras estratégias que vão para além da simples informação da utilidade. É a análise da transição de um tipo de publicidade envolvendo uma proposta de venda utilitária ao consumidor para uma publicidade emocional que, através de signos e não apenas através do produto, apela ao desejo do consumidor, que será feita neste artigo. A base dessa análise assenta nas campanhas publicitárias dos sabões e sabonetes feitas na transição do século XIX para o século XX. Serão assim identificadas duas grandes tendências que marcaram a criação de campanhas publicitárias durante o século XX, a publicidade centrada numa proposta objectiva de compra do produto ("reason-why") e a publicidade "emocional" centrada nas aspirações sociais do desejo (SIVULKA, 2001). Ver-se-á como as campanhas criadas pela agência publicitária J. Walter Thompson para os fabricantes de sabões Woodbury's e Lux eram orientadas explicitamente por essas duas tendências. Ver-se-á de seguida como essas campanhas levaram a que as marcas se começassem a posicionar como um factor decisivo na criação da identidade do produto. Ver-se-á, finalmente, como a capacidade das marcas elas próprias atraírem os consumidores se foi, progressivamente, afastando daquela que sempre foi a filosofia subjacente às leis das marcas registadas

\section{SABÕES E SABONETES: DOIS CASOS}


As origens das marcas e da publicidade moderna: As campanhas publicitárias de sabões e sabonetes

de António Machuco Rosa

O surgimento das marcas de sabões e sabonetes deve ser situado no contexto histórico da evolução milenar da higiene pessoal. Até muito recentemente, a higiene pessoal era um comportamento que a generalidade das pessoas raramente praticava. Ela estava confinada a castas sociais dominantes, nas quais a limpeza estava provavelmente associada à purificação, reenviando assim para uma origem religiosa (cf. SMITH, 2007). Esse facto mostra que a higiene pessoal não possui uma absoluta essência funcional a que os indivíduos naturalmente sempre teriam aspirado. É apenas durante o século XIX, em particular nos Estados Unidos, que o hábito da higiene corporal começou a tornar-se comum. Isso não ocorreu sobretudo por as pessoas terem finalmente despertado para as vantagens medicinais de ter um corpo asseado. Mesmo se a limpeza sempre esteve associada à superioridade moral da brancura e a sujidade à inferioridade da negritude, a higiene pessoal emergiu durante o século XIX por atestar um comportamento refinado que muitas pessoas começaram a imitar (APPLEGATE, 2012: 100). Em especial, a classe média norte-americana começou a definir-se a si própria enquanto classe de consumo através do ensaboamento frequente do corpo. $\mathrm{O}$ uso de sabão para lavar a pele tornou-se uma moda que era o signo de uma verdadeira identidade individual (cf. SIVULKA, 2001).

A natureza social da importância da limpeza através do uso de sabões não impede que o aspeto utilitário dessa prática seja real. Se o uso de sabão se desenvolveu como uma prática cultural, esta tem evidentemente uma afinidade com o aspeto biologicamente utilitário da higiene do corpo. Retomando uma ideia que Thorstein Veblen (1994 [1899]) desenvolveu precisamente no período histórico sob análise, pode dizer-se que se o prestígio foi determinante na adoção do sabão, ele veio naturalmente acompanhado do aspeto funcional: existe afinidade natural entre prestígio e funcionalidade. A funcionalidade - a higiene corporal, neste caso - ela própria torna-se um signo de prestígio. A conjugação desses dois aspetos é importante para compreender as campanhas publicitárias das primeiras marcas de sabão; na realidade, foram as marcas dos novos produtos de higiene que em larga medida iniciaram a publicidade moderna. Apresentam-se de seguida dois exemplos que mostram como se transitou de uma publicidade baseada na informação sobre a utilidade do produto para um tipo de anúncios cada vez mais salientando o prestígio associado ao consumo de bens correntes. 
As origens das marcas e da publicidade moderna: As campanhas publicitárias de sabões e sabonetes

de António Machuco Rosa

\subsection{Woodbury's}

A passagem de uma dinâmica utilitária para uma destinada a conferir uma qualidade ao serviço do prestígio é exemplificada pelo "Woodbury's". Ele foi criado por volta de 1870 como uma medicina patenteada por John Woodbury, um dermatologista que alegava que o produto curava doenças da pele (SUTON, 2009: 105).

Fig. 1 - A marca "Woodbury's Facial Soap"

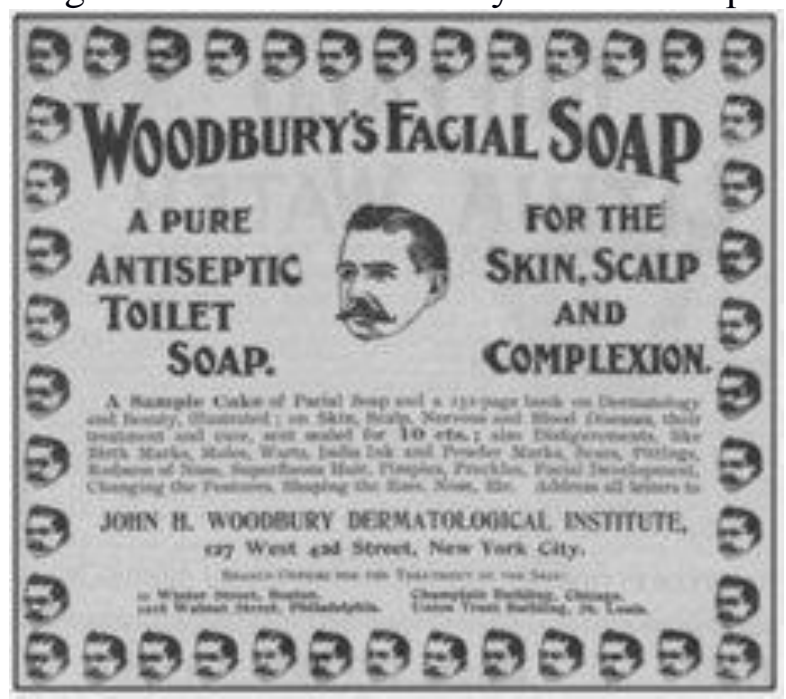

Em 1901, John Woodbury vendeu a sua companhia à Jergens Co. Em particular, vendeu a marca 'Woodbury's Facial Soap'. De seguida, em 1907, ele fundou uma nova empresa e começou a comercializar um sabão que designou por "Woodbury's New Skin Soap". Em consequência, a Jergens Co. moveu um processo judicial para impedir o uso desse nome assim como impedir que qualquer sabão tivesse como parte do seu nome "Woodbury", com o fundamento de que o público consumidor podia ser enganado. O tribunal aceitou, afirmando que, ao comprar "Woodbury's New Skin Soap", os consumidores podiam, falsamente, julgar que estavam a comprar um produto fabricado pela empresa que tradicionalmente produzia "Woodbury's Facial Soap", a Jergens Co. ${ }^{2}$

Esta litigância exemplifica qual é o fundamento da lei de marcas registada, e que então se estava a tornar dominante. Nos inícios do século XX, como sucedeu na lei norte-americana de 1905, as leis das marcas registadas começaram a tornar definitivamente claro que a proteção da marca consiste em proibir que um certo

${ }^{2}$ Cf. Andrew Jergens Co. v. Bonded Products Corporation, 21 F.2d 419 (2d Cir. 1927). Disponível em: http://law.justia.com/cases/federal/appellate-courts/F2/21/419/1510012/. Acesso em: 31/12/2015. 
As origens das marcas e da publicidade moderna: As campanhas publicitárias de sabões e sabonetes

de António Machuco Rosa

indivíduo ou empresa use uma marca, idêntica ou similar a outra marca já registada, na designação de um produto que seja idêntico ou similar ao produto do indivíduo ou empresa que originalmente registou essa marca em conexão com o seu produto (cf. BARTHOLOMEW, 2008: MCKENNA, 2007). Noutros termos, a infração da lei não consiste em usar a marca ela própria (o signo), mas sim no facto de uma marca denotando um certo produto usualmente fabricado por uma certa empresa passar também a ser usada por uma outra empresa para designar um produto similar, levando a que os consumidores julguem, falsamente, que este produto é também fabricado pela primeira empresa (a empresa fabricante) do produto, origem essa que se supõe ser um certificador da qualidade constante do produto. No caso, Jergens Co. v. Woodbury, Jergens Co. acusava John Woodbury de, ao usar a marca "New Skin Soap", ele estar a induzir os consumidores no erro de julgar que a empresa que produzia e vendia "Wo«odbury's New Skin Soap" era a mesma que sempre estava na origem do produto denotado pela marca "Woodbury's Facial Soap".

A legislação sobre as marcas registadas tem, até recentemente, subjacente a ideia de que uma marca é uma estrutura triádica composta por um nome (a marca) que refere um produto que reenvia a uma origem garante da sua qualidade constante (cf. BEEBE, 2010). Não é esse o significado intuitivo que hoje em dia é muitas vezes associado ao conceito de marca: forma-se a ideia, em larga medida falsa, de que se protege a própria marca (o nome), e não a ligação à origem. Como se referirá no final deste artigo, apenas recentemente começaram a existir iniciativas legislativas que protegem a própria marca. De facto, a ideia de que a lei supostamente protegeria as próprias marcas, o nome da marca, decorre em parte do facto de os fabricantes terem cada vez mais a acentuado a identidade da marca que denota um certo produto. Mesmo que de forma ainda relativamente ténue, as campanhas das marcas de sabões do início do século XX já apontavam nesse sentido.

Essa evolução já se nota em Woodbury’s Facial Soap. O sabão estava no início indissoluvelmente ligado ao produto e à sua origem (John Woodbury) que certificava esse produto, fazendo-se igualmente uma proposta de venda assente em propriedades medicinais e higiénicas. Esta orientação manteve-se quando a Jergens Co comprou a marca e durante o período de litigância com John Woodbury. Contudo, o problema foi que as vendas não cessaram de diminuir (SUTON, 2009:106). Em consequência, na 
As origens das marcas e da publicidade moderna: As campanhas publicitárias de sabões e sabonetes

década seguinte, o sabão vai ser radicalmente reposicionado quando a já então grande agência de publicidade J. Walter Thompson desenvolveu uma campanha totalmente inovadora para a época. A campanha foi criada pela copywriter Helen J. Landsdowne, e o resultado foi que as vendas de Woodbury's em 1921 já eram vinte vezes superiores às de 1910 (Ibidem: 107). A enorme força da publicidade como operadora de escolha e orientadora do desejo dos consumidores ficou cada vez mais clara.

A campanha criada por Helen Lansdowne foi baseada no slogan "A Skin You Love to Touch", e terá sido a primeira campanha a usar sistematicamente o sexo na publicidade moderna (POPE, 2003). Além disso, enquanto no caso da publicidade da maioria dos sabões da época, a barra de sabão - e assim o signo referindo o produto estava no centro do anúncio, tal como sucedia com o nome "Woodbury's Facial Soap" em campanhas anteriores desse sabão (cf. Fig. 4), já no caso da campanha criada pela J. Walter Tompson o destaque vai para a frase "A Skin You Love to Touch" e a barra de sabão apenas aparece num canto da página. A campanha deixou de se centrar nas características e na utilidade objetiva do produto para se centrar nas interações sociais que ele inspirava (cf. Fig. 2).

Fig. 2 - Dois anúncios, de 1915 e 1917, da campanha "A Skin you love to touch"
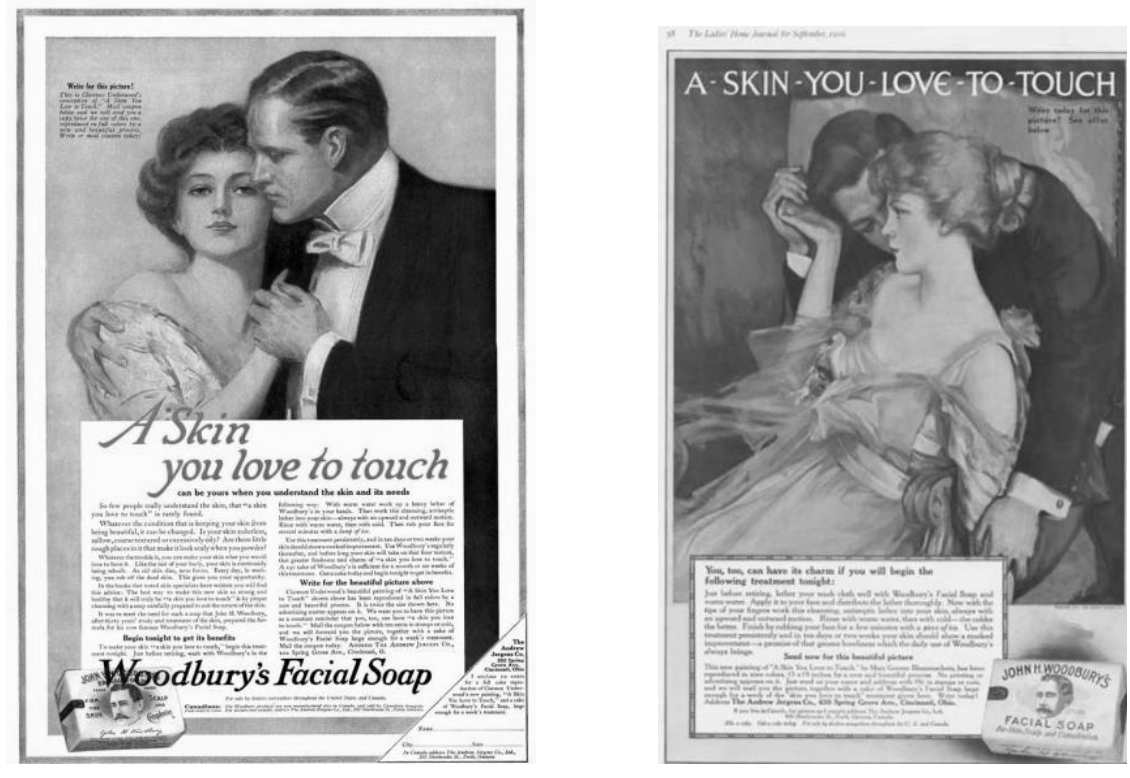

Uma publicidade centrada nas interações sociais tende a relegar para segundo plano as características objetivas dos produtos. Essa publicidade veicula um conteúdo aspiracional que envolve a imaginação acerca dos outros. Os anúncios do sabão para a face não se destinavam a mulheres reais que se encontravam efetivamente na situação 
As origens das marcas e da publicidade moderna: As campanhas publicitárias de sabões e sabonetes

que eles descreviam, isto é, não se dirigiam às mulheres de classes relativamente afluentes que eram desejadas e cortejadas por homens galãs igualmente afluentes. Os anúncios exemplificados na Fig. 2 dirigiam-se antes a mulheres que aspiravam à situação das mulheres representadas nos cartazes da campanha (Pope, Idem). Dirigiamse às mulheres espetadoras do anúncio e nas quais se procurava potenciar o desejo de ser objeto do mesmo desejo de que a modelo do anúncio é objeto. As modelos dos anúncios surgem como modelo do desejo das mulheres consumidoras que, através do uso de Woodbury's, poderiam adquirir o ser desejado das modelos.

O tipo de campanha "A Skin You Love to Touch" estava destinado a ter o sucesso que também tiveram inúmeros anúncios do mesmo género, desenvolvidos ao longo do século XX. No espírito de Helen Lansdowne, a campanha Woodbury's era orientada pelas duas forças potencialmente divergentes da publicidade moderna. Por um lado, existe a publicidade "reason-why", proposta inicialmente por John E. Kennedy em 1904, e caracterizada pela apresentação de um argumento específico centrado no produto que leve à sua compra (LEARS, 1994: 198; SIVULKA, 1998: 107). Por outro lado, existe a publicidade que criativos como Theodore MacManus e Raymond Rubican designavam por "publicidade atmosférica" (ou "publicidade emocional"), e que gira "em torno de sugestões veiculando a impressão de integridade, qualidade, prestígio" (SIVULKA, 1998: 113). Essas duas tendências na publicidade sempre coexistiram e elas eram um guia orientador da J. Walter Thompson. A agência estimava que uma campanha como a de Woodbury's representava precisamente um exemplo da coexistência entre as duas grandes duas formas de conceber anúncios. Segundo a própria Helen Lansdowne, "A Skin You Love To Touch" era "30 \% sentimento e 70 \% tratamento", onde os $70 \%$ eram certamente ganhos com o texto que acompanhava a imagem. Já em 1921 a proporção alterava-se para 40-60\%, "talvez porque o sucesso emocional do apelo a uma pele suave e acariciável se tinha tornado irresistível" (SUTTON, 2009: 110). O “emocional" é da ordem do "atmosférico", isto é, do desejo intangível assente mais em interações sociais do que em qualidades objetivas do produto. Na época, ainda era difícil admitir que uma campanha assentasse quase exclusivamente no emocional. É no entanto claro que se verificou nessa altura uma transição histórica da publicidade "reason why" para a publicidade emocional assente no ser, no estilo pessoal e no desejo que os sujeitos do anúncio despertavam. A 
As origens das marcas e da publicidade moderna: As campanhas publicitárias de sabões e sabonetes

de António Machuco Rosa

identidade da marca deveria veicular esses valores emocionais. Na realidade, foi ainda a J. Walter Thompson que consumou completamente essa transição, como atesta um segundo exemplo de campanha publicitária de sabões, a que lançou o sabonete de banho Lux.

\subsection{Lux}

A Lever Brothers foi criada em Inglaterra, em 1851, como mais uma das lojas destinadas a vender produtos a granel. Em 1885, a empresa lançou a sua primeira barra de sabão com marca, Sunlight Soap, a que se seguiu o seu primeiro grande sucesso comercial, o sabão Lifeuoy. Em 1900 foi lançado, primeiro em Inglaterra depois nos Estados Unidos, o sabão Lux. A originalidade deste produto consistia em ser uma forma de sabão em pó proposta como uma vantajosa alternativa ao tradicional sabão em barra. A Lever propôs Lux como uma marca que distinguia o seu produto dos sabões genéricos, comercializando-o em embalagens standard e com o nome bem destacado no anúncio. A proposta - portanto, a utilidade - associada ao produto consistia, inicialmente, em afirmar que a lavagem com Lux não fazia encolher as lãs (cf. Fig. 3: “Lux won't shrink woollens"). ${ }^{3}$

Fig. 3 - O sabão Lux em pacote e prometendo não encolher as lãs (1900)
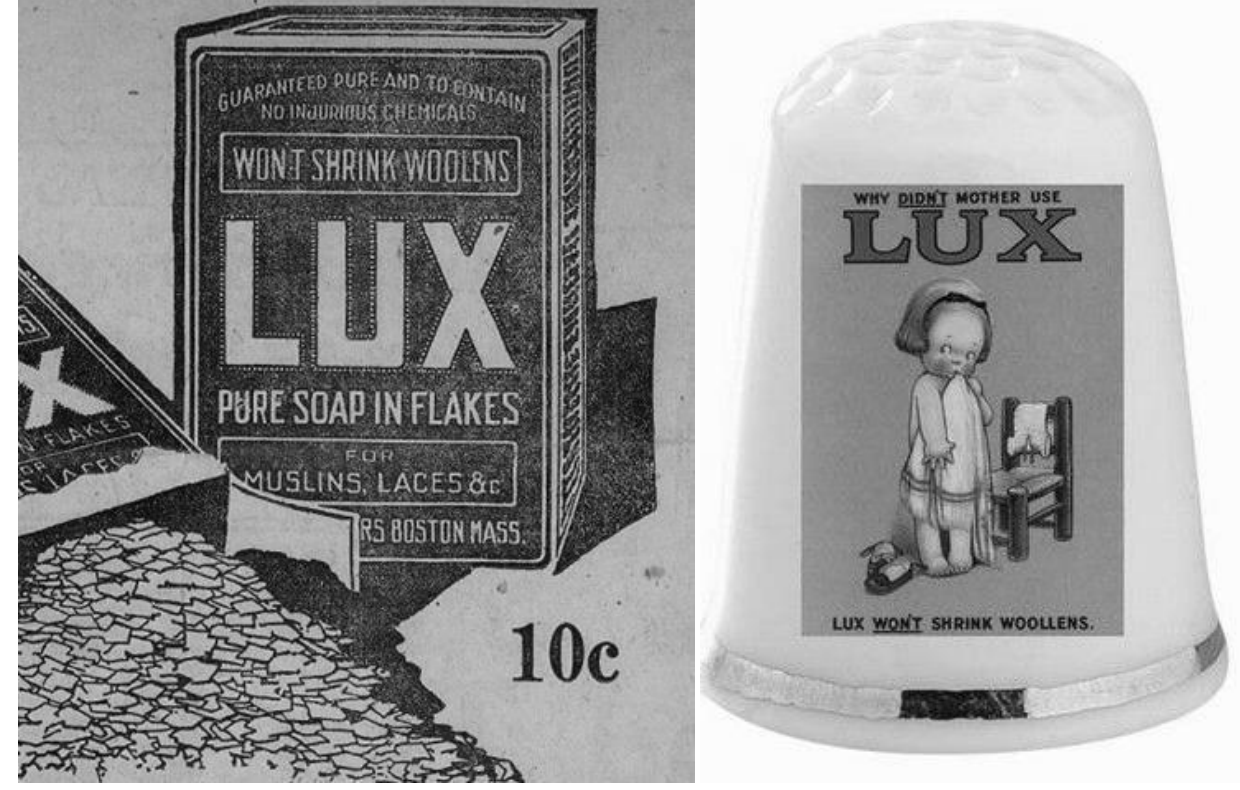

\footnotetext{
${ }^{3}$ Sobre as campanhas de Lux criadas pela da J. Walter Thompson, cf. Stefan Schwarzkopf (2008).
} 
As origens das marcas e da publicidade moderna: As campanhas publicitárias de sabões e sabonetes

de António Machuco Rosa

Quando, a partir de 1906, a Lever começou a comercializar Lux nos Estados Unidos, a empresa recorreu aos serviços da J. Walter Thompson. Tal como faria com Woodbury's, a agência procurou reposicionar Lux, direcionando-o inicialmente para classes sociais com capacidade financeira para adquirir um vestuário mais dispendioso que necessitasse de manter-se em bom estado após a lavagem. O reposicionamento levou também a propor Lux como um produto que podia ser usado para lavar todo o tipo de tecidos delicados (cf. Fig. 4).

Fig. 4 - Um anúncio de 1919: Lux deixa em bom estado os tecidos delicados

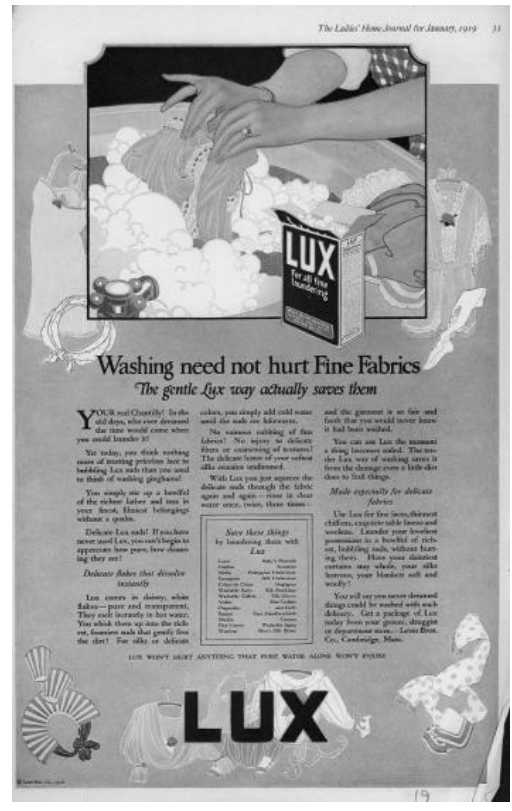

Sempre graças aos esforços da J. Walter Thompson, a partir da segunda década do século XX Lux deixou de estar centrado apenas na utilidade e começou a ficar associado a estilos de vida dispendiosos, sendo também associado às mulheres que, nos Estados Unidos, começavam a aderir às novas tendências da moda assentes em vestidos simples de inspiração desportiva. Essas mulheres trocavam frequentemente de roupa, e a sua lavagem com Lux permitia a sua preservação (cf. Fig. 5). 
As origens das marcas e da publicidade moderna: As campanhas publicitárias de sabões e sabonetes

de António Machuco Rosa

Fig. 5 - Lux é associado às novas tendências do vestuário feminino. O anúncio é de 1920.

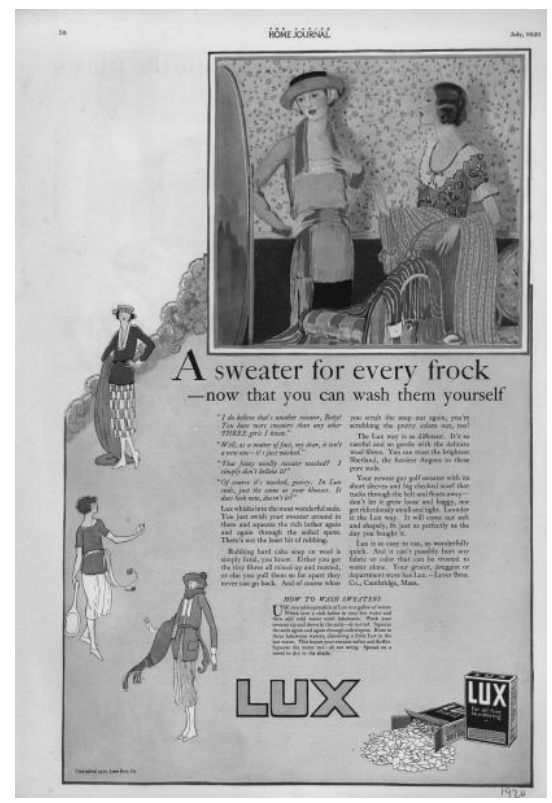

Por meados dos anos vinte, a J. Walker Thompson deu mais um passo na criação publicitária e passou a ligar a marca Lux àquela que durante muitos anos seria a sua imagem de marca, o recurso a celebridades, como estrelas de cinema e membros da realeza.

Fig. 6 - Lux, as estrelas de cinema, e a realeza (1925)

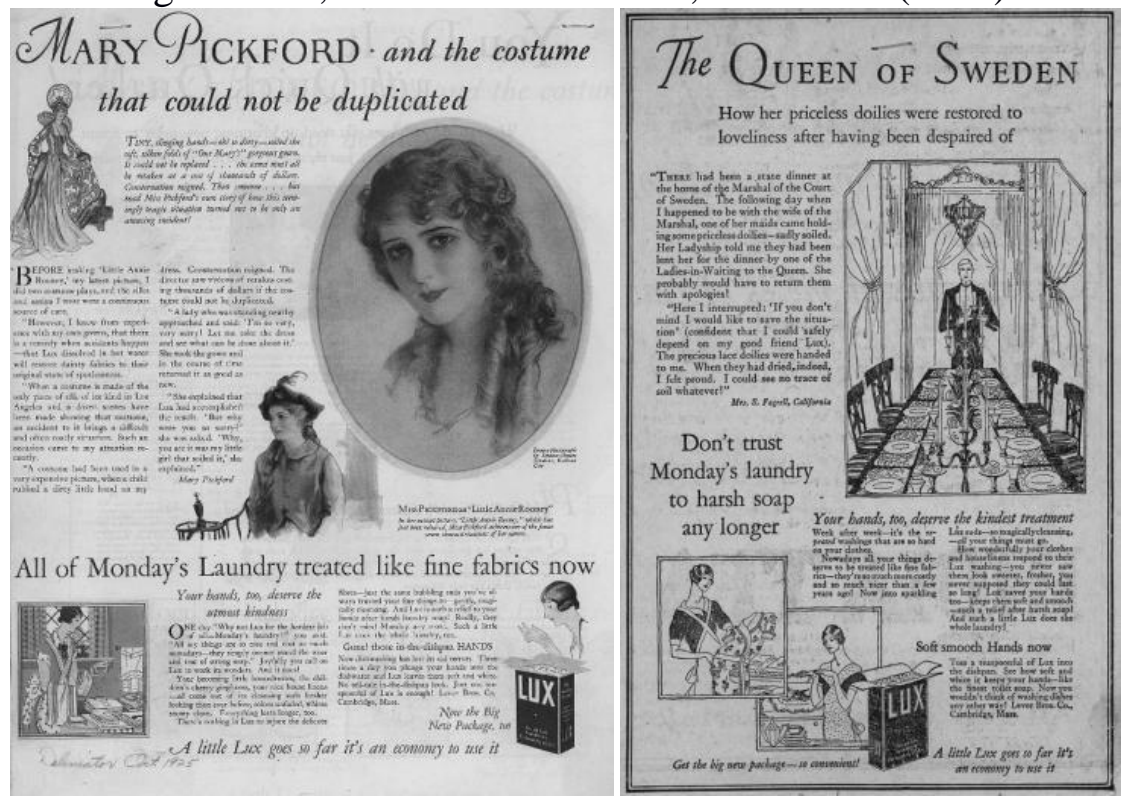


As origens das marcas e da publicidade moderna: As campanhas publicitárias de sabões e sabonetes

de António Machuco Rosa

Ainda em meados dos anos vinte, a agência publicitária realizou para a Lever um conjunto de trabalhos de campo, que hoje designaríamos por estudos de marketing, e que permitiram concluir que um número crescente de pessoas estava a utilizar o produto Lux para outros fins para além dos explicitamente visados pela empresa fabricante. Em vez de ser apenas utilizado para lavar roupa, Lux estava também a ser utilizado para lavar as mãos e o cabelo. Foi no seguimento dessa descoberta que a Lever lançou um futuro ícone publicitário, o sabonete de banho Lux. Paralelamente, em 192728, inicialmente em Inglaterra, a Walter Thompson concebeu uma nova campanha publicitária da Lux que prolongou as tendências que já se vinham a manifestar no passado, mas que, ao mesmo tempo, centrou definitivamente a marca Lux em torno dos estilos de vida da mulher moderna sofisticada, quer dizer, em torno do desejo de manifestar uma identidade pessoal superior. Essa nova campanha da Lux rompeu definitivamente com as formas tradicionais de publicidade de sabões (SCHWARZKOPF, 2008). Rompeu com a campanha de Woodbury's centrada na sedução e desejo sexual. E rompeu ainda mais claramente com as formas mais tradicionais de publicidade de sabão assentes em imagens de donas de casas a realizar tarefas domésticas na cozinha ou na casa de banho (veja-se a Fig. 7).

Fig. 7 - À esquerda, um anúncio de Lux seguindo a publicidade tradicional centrada em tarefas domésticas. À direita, um anúncio do sabão Ivory Soap.
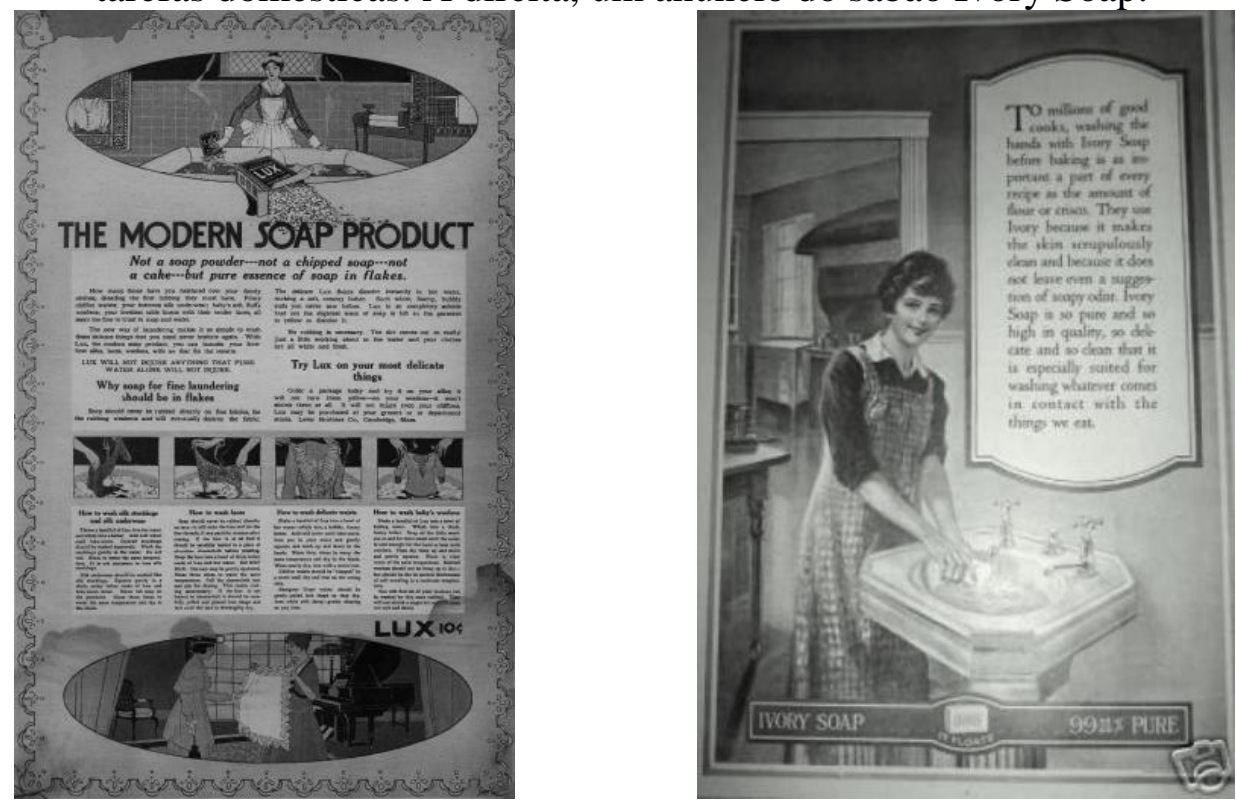
As origens das marcas e da publicidade moderna: As campanhas publicitárias de sabões e sabonetes

de António Machuco Rosa

A campanha de 1927/28 abandonou por completo a ideia de que comprar Lux era comprar sabão, assim prosseguindo a tendência anterior de posicionamento da marca. Passou antes a tentar vender-se a ideia de limpeza e, sobretudo, a campanha assentou nos temas da moda e do mundo do estilo, prestígio e sedução. Como é referido explicitamente no documento divulgado à imprensa pela J. Walker Thompson, o objetivo da campanha "era mudar a perceção do produto [Lux] enquanto apenas um produto de sabão em pó diferente, para passar a ser uma espécie de produto mágico" (In SCHWARZKOPF, 2008: 23). Ou, nas palavras do presidente da Lever, A. Countway, Lux deveria ser colocado num "pináculo, sem qualquer ligação a roupa suja e tanques de lavar roupa" (In SIVULKA, 2001: 122).

A diferenciação de produto já não assentava nas caraterísticas próprias do sabão em pó Lux. A J. Walter Thompson deixou de procurar diferenciar Lux através de uma proposta "reason why" objetiva, como ainda em parte sucedia com Woodbury's. O que passou exclusivamente a ser proposto foram os valores e emoções associados ao produto e, portanto, a forma como ele interagia com o ser social da consumidora. Essa interação, o ser que o sabonete Lux conferia, era o prestígio, o glamour do estilo sofisticado da mulher moderna que estava definitivamente na moda - a mulher que seguia a nova moda dos trajes desportivos naturalmente adaptados ao corpo que tinha sido introduzida por casas de costura como Chanel. Veja-se a Fig. 8. 
As origens das marcas e da publicidade moderna: As campanhas publicitárias de sabões e sabonetes

de António Machuco Rosa

Fig. 8 - Os anúncios Lux em 1928. Exibem-se mulheres sofisticadas dentro do estilo desportivo que então era a nova moda.

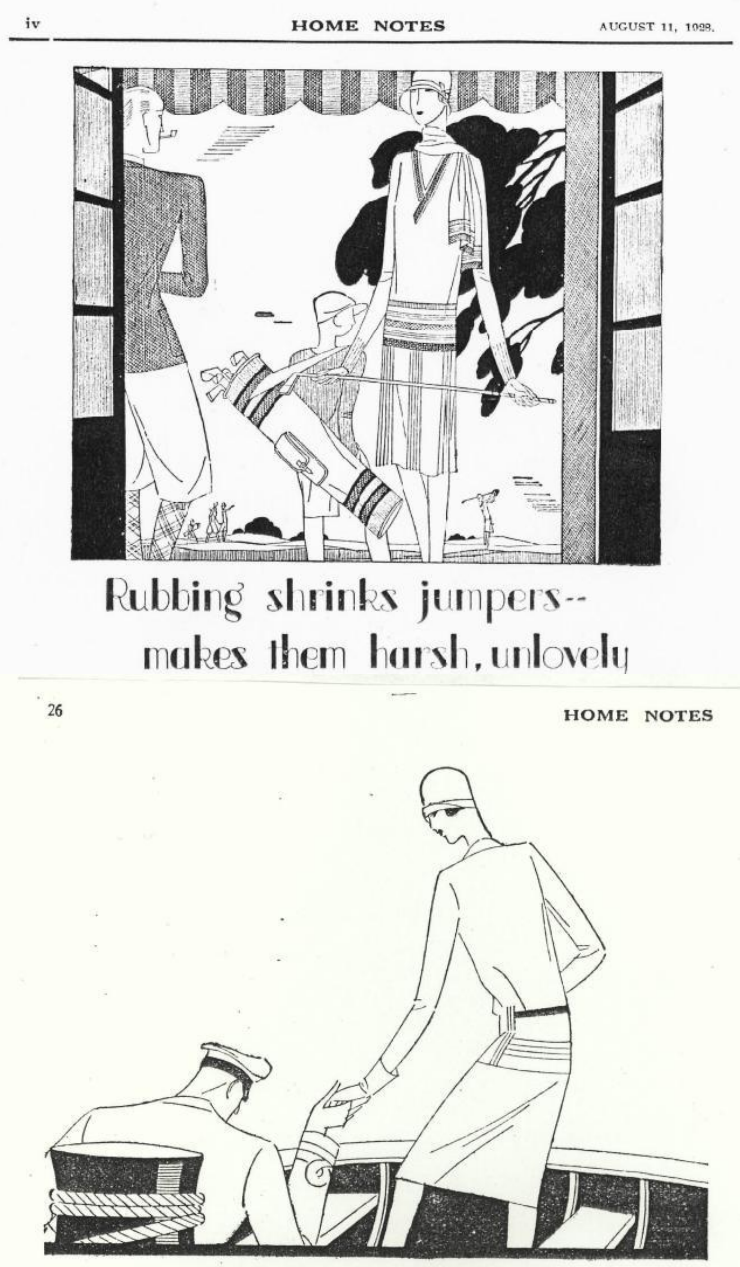

Rubbing shrinks jumpers:makes them harsh, unlovelu

A trajetória das campanhas da Lux nas primeiras três décadas do século XX revela uma tendência nítida. Primeiro, existiu a ênfase no empacotamento do produto e no seu uso para certas finalidades específicas (não encolher as lãs), dispensando o tradicional sabão em barra. De seguida, surgiu a ideia publicitária de que, mais que vender "sabão", Lux era a venda de limpeza e higiene pessoal. Depois, a proposta de Lux foi que o produto devia ser adotado por classes relativamente ricas, que queriam lavar diversas vezes os seus tecidos delicados. Seguiu-se o recurso a celebridades. Finalmente, mais do que "sabão" e "higiene", Lux passa a estar associado ao prestígio, ao glamour, à moda, isto é, à personalidade ou ser da consumidora na sua relação com outros seres humanos que lhe servem de modelos. É essa trajetória que permite sustentar que a campanha Lux de 1928 antecipou a publicidade baseada em estilos de 
As origens das marcas e da publicidade moderna: As campanhas publicitárias de sabões e sabonetes

de António Machuco Rosa

vida (lifestyles), que se tornaria dominante a partir dos anos sessenta (SCHWARZKOPF, 2008).

A estratégia publicitária de Lux foi delineada pela agência J. Walter Thompson. É inteiramente correto afirmar que essa agência foi a principal fundadora da publicidade moderna. Ela foi responsável por diversas inovações na conceção e distribuição de publicidade. Viu-se qual foi a estratégia seguida no caso da conta Woodbury's. Na campanha para esse sabão, já existia a ênfase na comunicação ao consumidor de um desejo de ser. É notável como, no início do século XX, era claro para agência norteamericana que a publicidade não se baseava apenas numa proposta objetiva de compra e no recurso a imagens visualmente atraentes, mas na capacidade de "criar desejo pelo produto publicitado" (J. WALTER THOMPSON, 1911:31).

A publicidade é uma forma de comunicar o desejo. A frase anteriormente citada foi escrita em 1911 e ainda pode ter alguma ambiguidade, pois por "desejo" pode ser entendido apenas o desejo da utilidade que o produto confere. No entanto, o exemplo da evolução das campanhas Woodbury's e Lux mostra que o "desejo" tendeu progressivamente para o desejo associado a personalidades, à qualidade prestigiosa que pode ser adquirida ao consumir o produto. Consumindo o mesmo produto que a personalidade consome, o espectador participa do seu ser, que consiste no seu prestígio, É uma qualidade que é um ser-para-os-outros. Esse tipo de prestígio era indiscutivelmente possuído pela estrela de cinema que usava Lux, e a promessa publicitária era que ele também poderia ser adquirido pela consumidora que imitasse a estrela de cinema. Lux não era um sabão destinado à higiene, mas sim um sabonete de banho que constituía um “produto mágico”. Se em 1911 os copyrighter's da J. Walter Thompson ainda não tornavam por escrito essa ideia completamente explícita, tal já sucedeu em 1927, precisamente no contexto da campanha de Lux. Escreveu nessa altura o diretor da agência, Stanley Resor:

"O espirito de competição (....). Queremos copiar aqueles que consideramos superiores em conhecimento, gosto ou experiência. $O$ desejo de emulação é maior nas mulheres que nos homens. Lombroso, o famoso psicólogo, explica isso em termos da habilidade feminina para ativar a sua imaginação com objetos externos" (In FOX, 1997: 90).

A publicidade respeita à "competição", "cópia" e "imaginação". A competição é o desejo de cada mulher de ser admirada por outras, posição que pode ser atingida 
As origens das marcas e da publicidade moderna: As campanhas publicitárias de sabões e sabonetes

de António Machuco Rosa

copiando o modelo que lhe mostra o ser pessoal prestigioso que está associado a um certo produto. Essa relação com o modelo desenrola-se sobretudo na imaginação, na imaginação que o destinatário do anúncio coloca no ser do modelo que lhe é mostrado. A utilidade do produto fica completamente contaminada pelo ser ou estilo pessoal que lhe fica associado.

A trajetória subsequente de Lux é bem conhecida. Durante muitos anos, os sabonetes Lux foram "os sabonetes usados pelas estrelas de cinema”. Em 1927, a J. Walter Thompson lançou uma nova campanha em que substituiu o tradicional desenho publicitário e, em fotografias, anunciou que " 9 em cada 10 estrelas de cinema tratam da sua pele com sabonete Lux". A associação de Lux ao glamour das estrelas de cinema tornou-se a uma componente central da imagem ou identidade de marca do sabonete fabricado pela Lever. O sucesso da campanha é atestado pelo facto de essa imagem de marca ter perdurado durante décadas.

Fig. 9 - A famosa campanha de Lux "9 em cada 10 estrelas de cinema usam o sabonete de banho Lux"

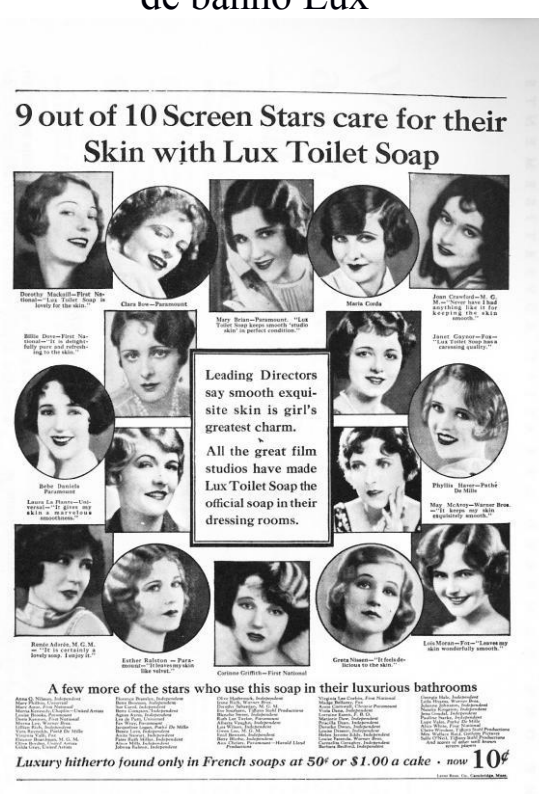

\section{CONCLUSÃO}

As campanhas publicitárias de sabões e sabonetes permitiram identificar dois grandes géneros de publicidade. Por um lado uma publicidade que prolongou o tipo de anúncios meramente informativos que acompanharam o surgimento das primeiras 
As origens das marcas e da publicidade moderna: As campanhas publicitárias de sabões e sabonetes

de António Machuco Rosa

marcas comerciais durante o século XIX. É a publicidade "lógica", "reason-why", que visa transmitir uma proposta de compra assente em reais, ou supostas, propriedades objetivas de um produto e que respondem a uma utilidade buscada pelo consumidor. Pode afirmar-se que se está, neste caso, perante uma estrutura diádica produto $\rightarrow$ utilidade do consumidor, em que pode ser negligenciada a influência de terceiros indivíduos nas escolhas de um indivíduo.

Contudo, procurou mostrar-se neste artigo que a este género de publicidade se seguiu uma publicidade que, no início do século XX, era designada por "emocional" ou "atmosférica", isto é, centrada no desejo envolvido nas interações sociais e apelando a qualidade intangíveis, "atmosféricas", como o estilo prestigioso. Nesse tipo de anúncio, a mensagem publicitária veicula a ideia de que, ao consumir o que o modelo consome, o espetador será objeto da mesma admiração por parte dos outros de que o modelo, ele próprio, é objeto. É uma estrutura triangular ilustrada na Fig. 10.

Fig. 10 - Estrutura triádica na publicidade "atmosférica"

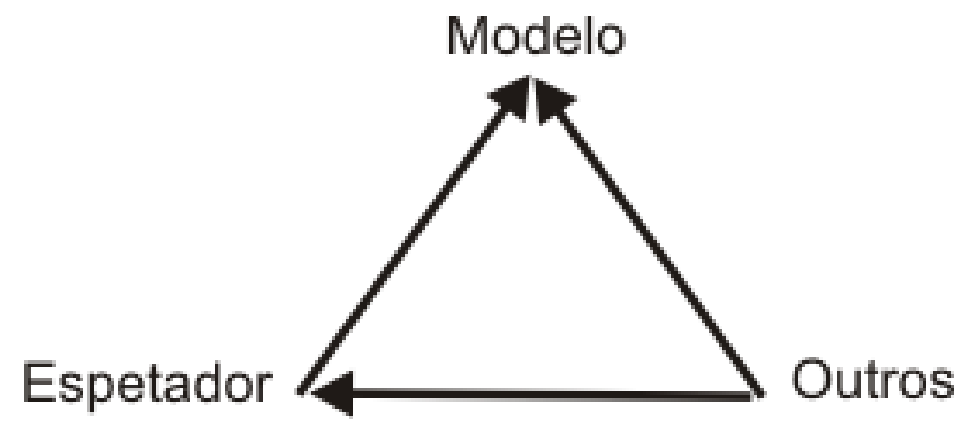

Aos dois tipos de publicidade também podem estar associadas diferentes formas de conceber o papel das marcas. Uma publicidade informativa e "reason-why" tende a estar acompanhada de uma concepção da marca em que a qualidade do produto que ela designa é certificada pelo indivíduo ou empresa que o produz. Mostrou-se neste artigo como esta concepção estava presente em produtos como os sabões certificados por John H. Woodbury. Nesse caso, a marca pouco mais é do que o simples nome que designa o produto e que reenvia para a sua origem. Este uso da marca estava perfeitamente de acordo com as leis das marcas registadas que surgiram durante o século XX: a função da marca (do nome) consiste em denotar um produto e reenviar à sua origem. Assim sendo, infringir uma marca registada consiste simplesmente no facto de terceiros usarem 
As origens das marcas e da publicidade moderna: As campanhas publicitárias de sabões e sabonetes

de António Machuco Rosa

uma marca (um nome) para denotar um produto com uma origem diferente daquela que o consumidor usualmente associa ao produto. Como acima se referiu, infringir uma marca consiste em quebrar a ligação estabelecida entre uma certa marca e uma origem que garante a reputação e qualidade constante do seu produto, com a consequência de confundir e enganar o consumidor. Nessa perspectiva, a estrutura das marcas comerciais legalmente traduzida nas leis da marcas é uma instância do triângulo semiótico. Recorde-se que, para o fundador da semiótica moderna, Charles S. Peirce, um signo é definido por três elementos em relação: o signo em si mesmo (uma palavra, um desenho, por exemplo), esse signo em si mesmo na sua relação com um objecto físico exterior no lugar do qual o signo em si mesmo se encontra, e o signo em si mesmo enquanto determina um interpretante, o qual "significa" o signo e se encontra na mesma relação para o objecto que o signo em si mesmo ele próprio se encontra (PEIRCE, 1931, Vol II). É este tipo de estrutura que se encontra subjacente à concepção clássica das marcas registdas. Apenas existe marca registada quando existe idêntica estrutura triangular, em que a marca ela própria corresponde ao signo em si mesmo de Peirce, o produto corresponde ao objecto e a origem e qualidade correspondem ao interpretante. Uma marca apenas é uma marca registada, isto é, um monopólio estatuído pela lei, quando estão presentes esses três elementos ligados entre si (cf. figura1). As leis das marcas registadas são a forma de preservar a integridade da relação entre os três termos do triângulo (BEEBE, 2010). Nesta conceção, os indivíduos não consomem marcas, o signo ele próprio e os valores que possa veicular. Eles não são orientados pela atracção e desejo de marca ele próprio.

Fig. 11 - Uma marca registada é uma estrutura triádica composta pela marca, produto e origem e qualidade

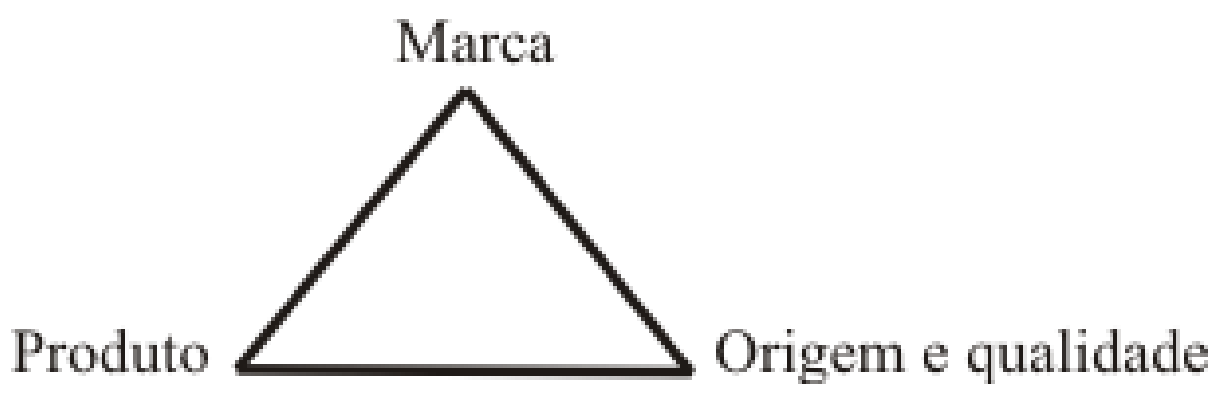


As origens das marcas e da publicidade moderna: As campanhas publicitárias de sabões e sabonetes

de António Machuco Rosa

No entanto, com o surgimento de uma publicidade salientando o prestígio que uma certa marca associa ao indivíduo que a usa, a função real das marcas deixa de ser a que está subjacente às leis tradicionais das marcas registadas. Se o conceito de identidade de marca ainda não estava tematizado quando a J. Walter Thompson lançou as campanhas Lux, já por essa altura se compreendia que a função de uma marca era muito maior do que a mera designação de um produto e da sua origem. Num texto escrito em 1927, na mesma altura em que surgiram as campanhas de Lux assentes em prestígio e glamour, Frank Schechter escreveu um artigo, The Rational Basis of Trademark Protection, destinado a ter uma enorme influência na área da propriedade intelectual, e no qual se que o "poder de uma marca" já então pouco tinha a ver com a identificação de uma origem do produto, mas sim com a sua capacidade em "estimular mais compras por parte do público consumidor" (SCHECHTER 1927: 818). Nas modernas realidades comerciais de uma sociedade de consumidores, a marca, o signo em si mesmo, não visa sobretudo garantir a reputação de qualidade constante ( goodwill) de um produto e empresa, mas sim criar essa reputação; a marca não garante essa reputação, antes a cria (Idem: 819). O signo-marca não é um simples nome que reenvia para uma realidade mais substancial, a única verdadeiramente importante, que seria a reputação de qualidade de uma empresa que fabrica um certo produto. Pelo contrário, "é a marca que realmente vende o produto" - não a utilidade -, e quando mais distintiva a marca maior o seu poder de venda (Ibidem). Portanto, para um autor como Schechter a protecção das marcas deveria incidir no seu carácter único, singular, na sua identidade que a diferencia de qualquer outra marca. Nesse sentido, a lei das marcas registadas deveria garantir direitos absolutos de propriedade ao detentor da marca. A lei deveria proteger o próprio nome, impedindo que este fosse usado para designar produtos com funcionalidades diferentes. Nesta conceção, dois dos vértices do triângulo semiótico - o produto e a origem - tendem a colapsar, ficando em destaque o signo ele próprio enquanto orientador do desejo de marca.

Assim, o uso efectivo das marcas em campanhas durante a década de vinte do século passado já apontava para uma realidade daquela que então estava codificada juridicamente. No entanto, a ideia de que a identidade da marca deveria ela própria ser legalmente protegida demorou bastante a ter alguma tradução legal. Durante décadas, a lei continuou a insistir na ficção segunda a qual a marca reenvia fundamentalmente a 
As origens das marcas e da publicidade moderna: As campanhas publicitárias de sabões e sabonetes

de António Machuco Rosa

uma origem, assim garantindo que os consumidores não são enganados. Apenas recentemente, em face da crescente importância comercial do poder de atração da própria marca, as leis passaram a incorporar cláusulas, designadas por cláusulas antidiluição das marcas. ${ }^{4}$ Apesar da ambiguidade dessas leis, elas traduzem um momento em que o quadro legal das marcas começa a estar em harmonia com práticas publicitárias existentes há quase um século quando produtos como sabões e sabonetes, preenchendo inicialmente uma função sobretudo utilitária, foram transformados numa proposta de prestígio veiculada através de uma marca.

\section{REFERÊNCIAS BIBLIOGRÁFICAS}

APPLEGATE, E. The Rise of Advertising in the United States: A History of Innovation to 1960. Lanha, Scarecrow Press, 2012.

BARTHOLOMEW, M. Advertising and the Transformation of Trademark Law In New Mexico Law Review. Vol. 38, 2008: 1-48.

BEEBE, B. Intellectual Property Law and the Sumptuary Code In Harvard Law Review, $\mathrm{n}^{\mathrm{o}}$ 4, vol 123, 2010:809-889.

COCHOY, F. Une histoire du marketing: Discipliner l'economie de marché. Paris, éditions de la Découverte, 1999.

FOX, S. The Mirror Makers. Chicago, University of Illiinois Press, 1997.

JONES, G. Beauty Imagined - A history of the global Beauty Industry. Oxford, Oxford University Press. 2010.

LEARS. J. Fables Of Abundance: A Cultural History Of Advertising in America. New York, Basic Books, 1994.

MAZA, R. Historia de la Publicidad.. Madrid, Eresma, 1999.

MCCARTHY, J. McCarthy on Trademarks and Unfair Competition. Eagan, West, 1996.

MCKENNA M. Normative Foundations of Trademark Law In The Notre Dame L. Rev, nº 5, vol. 82, 2007:1839-1916.

\footnotetext{
${ }^{4}$ Foi, no caso dos Estados Unidos, Lanham Act de 1995, que passou a incorporar uma clásula de antidiluição na sua seção 45. No caso da Europa, a Directiva Europeia sobre Marcas Registadas (Directiva 2008/95/CE) passou também a incorporar uma clásula desse tipo no Art. ${ }^{0}$ 5. (2)).
} 
As origens das marcas e da publicidade moderna: As campanhas publicitárias de sabões e sabonetes

de António Machuco Rosa

PEIRCE, C. S. Collected Papers of Charles Sanders Peirce. Vol I-VI, C. Hartshorne, P. Weiss (Eds.). Cambridge, Harvard University Press, 1931.

POPE, D. Making Sense of Advertisements In History Matters: The U.S. Survey on the Web, 2003. Disponível em: http://historymatters.gmu.edu/mse/ads/ads.pdf. Acesso em: 1/01/2016.

SCHECHTER, F. The Rational Basis of Trademark Protection In Harvard Law Review, $n^{0} 6$, vol 40, 1927:813-833.

SCHWARZKOPF, S. Turning Trade Marks into Brands: how Advertising Agencies Created Brands in the Global Market Place, 1900-1930, CGR Working Paper, 2008. Disponível em: http://webspace.qmul.ac.uk/pmartins/CGRWP18.pdf. Acesso em: 1/01/2016.

SIVULKA, J. Shared from Stronger Than Dirt: A Cultural History of Advertising Personal Hygiene in America, 1875-1940. New York, Humanity Books, 2001.

SIVULKA, J. Soap, Sex, and Cigarettes: A Cultural History of American Advertising. Boston, Wadsworth, 1998.

SMITH, V. Clean - history of personal hygiene and purity. Oxford, Oxford University Press, 2007.

SUTTON, D. Globalizing Ideal Beauty. New York, Palgrave, 2009.

VEBLEN, T. The Theory of the Leisure Class. New York, Penguin Books, 1994 [1899].

WALTER THOMPSON Co., J. (eds.). Things to know about trade-marks: a manual of trade-mark information. New York, J. Walter Thompson Co, 1911.

WILliAMS, R. Dream Worlds: Mass Consumption in Late Nineteenth-Century France. Los Angeles, University of California Press, 1982.

Artigo submetido: 03/06/2015

Artigo aprovado: 05/12/2015 